\title{
Asbestos, cement, and cancer in the right part of the colon
}

\author{
K Jakobsson, M Albin, L Hagmar
}

\begin{abstract}
Objective-The aim was to investigate associations between exposure to mineral fibres and dust, and cancer in subsites within the large bowel.

Design-Pooled retrospective cohort studies.

Subjects and settings-Blue collar workers, employed for at least one year in different trades; asbestos cement or cement workers $(n=2507)$, other industrial workers $(n=3965)$, and fishermen ( $\mathbf{n}=8092)$.

Main outcome measures-Standardised incidence ratios (SIRs, national reference rates) were calculated for cause specific cancer morbidity between 1958 and 1989. The observation period began 15 years after first employment.

Results-The asbestos cement and cement workers had a slightly increased risk of colorectal cancer (SIR 1.5; 95\% confidence interval (95\% CI) $1 \cdot 1-2 \cdot 0)$. This was due to an increase only in the right part of the colon (SIR 2.5; $95 \%$ CI $1 \cdot 6-3 \cdot 8)$. The ratio of right (7th revision of the International Classification of Diseases ICD-7) 1530-1531)/left (ICD-7 1532-1533) colon cancer among the asbestos cement and cement workers of 4.8 differed significantly from the ratio both among the other blue collar workers $(0.4)$ and among the fishermen $(1 \cdot 5)$. As the sensitivity and accuracy was insufficient, mortality data did not show the excess of cancers in the right part of the colon.
\end{abstract}

Conclusions-An increased incidence of cancer in the right part of the colon was evident in the asbestos cement and cement workers. The distribution of cancers within the colon was noticeably different from that in other blue collar workers, indicating that our findings cannot be explained by socioeconomic confounding factors. A detailed and appropriate disease classification, based on incidence data, is necessary in order not to obscure or underestimate effects of exposure in epidemiological studies on colorectcal cancer.

(Occup Environ Med 1994;51:95-101)

In occupational epidemiological studies wide categories of diagnoses such as "all gastrointestinal" or "colorectal" cancer are often used. These may be acceptable in studies with small numbers of cases where a detailed subdivision is not meaningful. If the agent under study has a harmful effect only in a specific site, however, this might easily be obscured by inappropriate disease classification.

There are reasons to consider cancer in the rectum and the anatomical subsites of the colon independently. ${ }^{1-3}$ The varying biological properties of proximal and distal segments of normal colonic epithelium and the physiological variations within the large bowel ${ }^{4}$ may be important determinants for dissimilarity in susceptibility to environmental agents. This hypothesis is supported by the finding that the risks of cancer associated with physical activity, ${ }^{5}$ secondary bile acids, ${ }^{67}$ and dietary components, ${ }^{8}$ are not uniformely distributed within the large bowel. Further, in a cancer registry based case-referent study, analyses by anatomical subsite showed that the excess risk for an occupational group was usually confined to a single subsite, which also suggests some specificity of effect. ${ }^{9}$ The evidence of different pathological, cytogenetic, and molecular features of proximal and distal colorectal cancer is rapidly accumulating. ${ }^{10}$ Despite this, subsite specific morbidity from cancer within the large bowel has not been reported before in cohorts of workers exposed to mineral fibres or dusts.

In recent studies of cement workers we have shown an excess risk of colorectal cancer. ${ }^{11} 12$ The excess risk was confined to the right part of the colon. ${ }^{12}$ Previously, we have also found an increased risk for colorectal cancer in a cohort of asbestos cement workers. ${ }^{13}$ The analysis was, however, not performed with respect to anatomical subsite. The aim of our present study was to further explore whether exposure to mineral fibres or mineral dust is a risk factor for cancer in the right part of the colon. The variations by sex, age, and social class in the incidence of cancer in the colon and rectum, may partly be mediated by differences in diet, body mass, and physical activity. Thus comparisons were made not only with the general population, but also with other cohorts of manual workers.

\section{Material and methods} COHORTS

Occupational cohorts studied at our department were reanalysed and, when possible, the observation period was extended until 1989. 
As a uniform inclusion criterion, a minimum of 12 months of employment was required. Further, the start of the study period was set to 15 years after first employment, as an extended induction latency time is appropriate for solid tumours. Only men were included. Table 1 and the next sections present some data on the cohorts. More detailed information is given in the original publications.

Workers exposed to mineral dust and fibres

The asbestos cement plant operated between 1907 and 1977, producing sheets, shingles, ventilation pipes, and various hand moulded details. ${ }^{13}$ The asbestos handled was mainly chrysotile (>95\%) and smaller amounts of crocidolite and amosite. Portland cement with low silica content $(<0.1 \%$ crystalline silica in the respirable fractions) was used. Only $15 \%-20 \%$ of the total workforce were continuously exposed to concentrations in air exceeding 2 fibres $(\mathrm{f}) / \mathrm{ml})$. Total dust concentrations were usually below $5 \mathrm{mg} / \mathrm{m}^{3}$, of which about $80 \%$ was cement dust. The cohort consisted of 981 native Swedish blue collar workers. Individual cumulative dose estimates (in $\mathrm{f}$-years $/ \mathrm{ml}$ ) were available for 823 workers. The median year of birth was 1913 (25 and 75 percentiles were 1905 and 1927 . Morbidity from tumours was studied between 1958 and 1989, mortality between 1958 and 1986.

Cement production in two separate plants started around 1920.12 Most workers were engaged in the cement production, but workers in the quarry were also included in the cohort. Total dust measurements during the early 1970 s were generally lower than 20 $\mathrm{mg} / \mathrm{m}^{3}$, later on below $10 \mathrm{mg} / \mathrm{m}^{3}$. The silica content in the dust was generally less than $5 \%$. In areas where the raw materials were handled, respirable crystalline silica concentrations were generally assumed to be less than $0.1 \mathrm{mg} / \mathrm{m}^{3}$ if the total dust concentration was below $10 \mathrm{mg} / \mathrm{m}^{3}$. Workers handling clinker and finished cement were exposed to substantially lower quartz concentrations. The cohort consisted of 1526 blue collar workers. The median year of birth was 1927 (25 and 75 percentiles were 1911 and 1941). Tumour morbidity and mortality were recorded between 1958 and 1986.

\section{Other industrial workers}

Industrial workers with various chemical exposures but with no significant exposure to mineral dust or fibres were selected as one of the comparison groups. Cohorts exposed to dust, which is persistent in the intestinal tract after inhalation and swallowing-for example, metal dust-were excluded. Exposure to other types of inorganic or organic dust may have occurred, however, as well as exposure to various suspected carcinogens.

In a chemical plant, carcinogens and suspected carcinogens such as piperazine, urethane, ethylene oxide, epichlorohydrine, and formaldehyde had been used in the synthesis and manufacture of a large number of organic chemical products. ${ }^{14}$ Production started in the 1940s. The cohort consisted of 313 blue collar workers. Morbidity and mortality from tumours were studied between 1958 and 1988.

In a fertiliser plant superphosphate had been produced since the end of the 19 th century and nitrate fertilisers since $1963 .{ }^{15}$ The workers had been exposed to nitrate dust, nitrous oxides, and acid mists. The cohort consisted of 1201 blue collar workers. Morbidity and mortality from tumours were studied between 1958 and 1988 .

In three leather tanneries, workers had been exposed to azo dyes, chromates, formaldehyde, vegetable tannins, and chlorophenols. ${ }^{16}$ The production in all plants started around 1900. The cohort consisted of 1156 blue collar workers. Tumour morbidity and mortality were recorded between 1958 and 1989.

In nine polyurethane foam manufacturing plants, workers had been exposed to toluene diisocyanate and methylene diphenyldiisocyanate. ${ }^{17}$ The production started between 1958 and 1974. The cohort consisted of 705 blue collar workers. Morbidity and mortality from tumours were studied between 1958 and 1987.

One hundred abattoir workers, 148 workers from a wool and polyester textile plant, and 342 sugar refinery workers originally formed part of a regional reference cohort of industrial workers, requiring similar professional skill and with similar work load as the asbestos cement workers. ${ }^{13}$ Morbidity from tumours was studied between 1958 and 1989, mortality between 1958 and 1986 .

In total, the cohort of other industrial workers consisted of 3965 men. The median year of birth was 1924 ( 25 and 75 percentiles were 1912 and 1940).

\section{Fishermen}

Members of fishermens organisations from the east ${ }^{18}$ and west coasts of Sweden formed another comparison group. Exposure to diesel exhausts, oils, tars, and ultra violet light had occurred during strenuous outdoor work. Moreover, the fishermen from the east coast had a high consumption of fatty fish contaminated with persistent organochlorine substances. The cohort consisted of 8092 fishermen. The median year of birth was 1922 (25 and 75 percentiles were 1909 and 1938). The observation period was between 1965 and 1988 for 6863 of them, and between 1968 and 1988 for the rest.

TUMOUR MORBIDITY AND CAUSE OF DEATH Information on at most two tumours, coded according to the 7th revision of the International Classification of Diseases (ICD7) was obtained from the Swedish Cancer Registry. Information on the cause of death was obtained from Statistics Sweden. The death certificates were coded according to ICD-8 by Statistics Sweden, which is responsible for the coding of all Swedish death certificates. 
ESTIMATES OF RISK

Expected morbidity from cancer for the period between 1958 and 1989 (or the appropriate period) was calculated by cause, calendar year, and five year age group specific rates for males in Sweden. These rates were calculated from cancer and population counts obtained from the Swedish Cancer Registry and Statistics Sweden. Date of diagnosis of a tumour, date of death, or emigration were used as individual endpoints. Similarly, the expected mortality in the period between 1958 and 1989 (or the appropriate period) was calculated.

\section{ANALYSIS}

Standardised mortality rates (SMRs), cause specific standardised incidence rates (SIRs), and $95 \%$ confidence intervals $(95 \% \mathrm{CIs})$ were calculated according to the Poisson distribution, with $\chi^{2}$ approximation if the expected values were greater than 10 . Differences in the location of colon cancers between study groups were examined by Fisher's exact test (two tailed). Significance refers to a lower limit of the $95 \%$ CI for SMR and SIR that excludes 1.00 or $p<0.05$.

\section{Results \\ MORTALITY AND MORBIDITY FROM ALI CANCERS}

The overall mortality among the asbestos cement workers was slightly higher than in the general population, SMR $1 \cdot 14$ (95\% CI 1.03-1.25). The cement workers had an SMR of $1.02(95 \%$ CI $0.92-1 \cdot 13)$, and the other industrial workers an SMR of 1.01 (95\% CI 0.95-1.08). By contrast, the fishermen had a low mortality, SMR 0.85 (95\% CI $0 \cdot 81-0 \cdot 89$ ).

The overall incidence of cancer was raised among the asbestos cement workers, SIR 1.38 (95\% CI 1.20-1.59), and also among the other industrial workers, SIR 1.15 (95\% CI 1.05-1·27). By contrast, the fishermen had a low incidence of cancer SIR 0.91 (95\%
CI 0.84-0.98). The cement workers had an SIR of $0.91(95 \%$ CI $0 \cdot 76-1 \cdot 09)$.

\section{MORBIDITY FROM COLORECTAL CANCER}

The morbidity from colorectal cancer (ICD-7 153-154) was increased among both the asbestos cement workers (SRI 1.40) and the cement workers (SIR 1.58). The combined SIR was 1.49 (95\% CI 1.12-1.95). The increased risk was mainly explained by an increase of cancers in the right part of the colon (SIR 2.49; 95\% CI 1.62-3.76; table 1). This corresponds to about 0.4 extra cases/1000 person-years among the workers exposed to minerals in addition to the expected number, $0 \cdot 25 / 1000$ person-years. By contrast, the estimated risk of cancer in the left part of the colon was low (SIR 0.55 $(95 \%$ CI $0 \cdot 18-1 \cdot 30)$. The observed ratio of right/left colon cancer was 4.8 for the workers exposed to minerals (12 among the asbestos cement workers and three among the cement workers). This ratio can be compared with the ratio of $1 \cdot 1$, derived from the expected number of cases in the cohorts.

Among the other industrial workers, the SIR for cancer in the right part of the colon was 0.44 (95\% CI $0.16-0.97)$, and for cancers in the left part $1 \cdot 12$ (95\% CI 0.61-1.88). Hence, the location of cancers within the colon differed significantly from that in the mineral exposed workers (right/left ratio $0.4 v$ $4.8(p=0.0003))$. Among the fishermen the SIR for cancer in the right part of the colon was 1.03 (95\% CI 0.71-1.47) and for cancers in the left part SIR $0.76(95 \%$ CI $0 \cdot 47-1 \cdot 18)$. The right/left ratio found was $1 \cdot 5$, which differed significantly from that in the workers exposed to minerals $(p=0.05)$.

There was also an increased incidence of rectal cancer among both the mineral exposed workers, (SIR $1.60 \quad(95 \% \quad$ CI $1 \cdot 03-2 \cdot 41)$ ) and the other industrial workers (SIR 1.52 (95\% CI 1.05-2.17)). This corresponded to about 0.2 extra cases $/ 1000$ person-years in the combined industrial worker cohorts as well as the expected incidence of

Table 1 Site specific morbidity from colorectal cancer in cohorts of manual workers (the observation period begins 15 years after start of employment)

\begin{tabular}{|c|c|c|c|c|c|c|c|c|c|c|c|c|c|c|}
\hline \multirow[b]{3}{*}{ Cohort } & \multirow[b]{3}{*}{ No } & \multirow{3}{*}{$\begin{array}{l}\text { Person- } \\
\text { years }\end{array}$} & \multicolumn{4}{|c|}{ Right part of the colon } & \multicolumn{4}{|c|}{ Left part of the colon } & \multicolumn{4}{|c|}{ Rectum } \\
\hline & & & \multicolumn{4}{|c|}{ ICD 1530-1531 } & \multicolumn{4}{|c|}{ ICD 1532-1533 } & \multicolumn{4}{|c|}{$I C D 154$} \\
\hline & & & $O$ & E & $S I R$ & $(95 \% C I)$ & $O$ & E & $S I R$ & $(95 \% C I)$ & $O$ & $E$ & SIR & $(95 \% C I)$ \\
\hline $\begin{array}{l}\text { Mineral dust and fibres } \\
\text { Asbestos cement } \\
\text { Cement } \\
\text { Total }\end{array}$ & $\begin{array}{r}981 \\
1526 \\
2507\end{array}$ & $\begin{array}{l}16708 \\
21341 \\
38049\end{array}$ & $\begin{array}{l}12 \\
12 \\
24\end{array}$ & $\begin{array}{l}5.04 \\
4.59 \\
9 \cdot 63\end{array}$ & $\begin{array}{l}2 \cdot 38 \\
2 \cdot 61 \\
2 \cdot 49\end{array}$ & $\begin{array}{l}(1 \cdot 23-4 \cdot 16) \\
(1 \cdot 35-4.57) \\
(1 \cdot 62-3 \cdot 76)\end{array}$ & $\begin{array}{l}1 \\
4 \\
5\end{array}$ & $\begin{array}{l}4 \cdot 72 \\
4 \cdot 31 \\
9 \cdot 03\end{array}$ & $\begin{array}{l}0.22 \\
0.93 \\
0.55\end{array}$ & $\begin{array}{l}(0.00-1 \cdot 18) \\
(0.25-2 \cdot 38) \\
(0 \cdot 18-1 \cdot 30)\end{array}$ & $\begin{array}{l}13 \\
11 \\
24\end{array}$ & $\begin{array}{r}7 \cdot 87 \\
7 \cdot 17 \\
15 \cdot 0\end{array}$ & $\begin{array}{l}7 \cdot 87 \\
7 \cdot 17 \\
1 \cdot 60\end{array}$ & $\begin{array}{c}(0.88-2.83) \\
(0.77-2.75) \\
(1.03-2 \cdot 41)\end{array}$ \\
\hline $\begin{array}{l}\text { Other industrial work: } \\
\text { Chemical plant } \\
\text { Fertiliser plant } \\
\text { Leather plant } \\
\text { Polyurethane plant } \\
\text { Abattoir } \\
\text { Sugar refinery } \\
\text { Textile plant }\end{array}$ & $\begin{array}{r}313 \\
1201 \\
1156 \\
705 \\
100 \\
342 \\
148\end{array}$ & $\begin{array}{r}2487 \\
18829 \\
20602 \\
3734 \\
1425 \\
4330 \\
3377\end{array}$ & $\begin{array}{l}1 \\
2 \\
2 \\
1 \\
0 \\
0 \\
0\end{array}$ & $\begin{array}{l}0.58 \\
4 \cdot 68 \\
4 \cdot 44 \\
0.77 \\
0.38 \\
1 \cdot 78 \\
0.86\end{array}$ & & & $\begin{array}{l}0 \\
5 \\
5 \\
0 \\
1 \\
2 \\
1\end{array}$ & $\begin{array}{l}0.55 \\
4 \cdot 37 \\
4 \cdot 20 \\
0 \cdot 62 \\
0 \cdot 35 \\
1 \cdot 66 \\
0 \cdot 79\end{array}$ & & & $\begin{array}{r}1 \\
11 \\
13 \\
2 \\
1 \\
3 \\
1\end{array}$ & $\begin{array}{l}0.91 \\
7.32 \\
7.05 \\
1.17 \\
0.57 \\
2.72 \\
1.32\end{array}$ & & \\
\hline Total & 3965 & 54784 & 6 & $13 \cdot 5$ & 0.44 & $(0.16-0.97)$ & 14 & 12.5 & $1 \cdot 12$ & $(0.61-1 \cdot 88)$ & 32 & $21 \cdot 1$ & 1.52 & $(1 \cdot 05-2 \cdot 17)$ \\
\hline Fishermen & 8092 & 98596 & 32 & $31 \cdot 1$ & 1.03 & $(0 \cdot 71-1 \cdot 47)$ & 21 & $27 \cdot 7$ & 0.76 & $(0 \cdot 47-1 \cdot 18)$ & 44 & $45 \cdot 6$ & 0.97 & $(0 \cdot 70-1 \cdot 31)$ \\
\hline
\end{tabular}

$\mathrm{O}=$ Observed tumours; $\mathrm{E}=$ expected tumours (from national rates). 
Table 2 Comparison of diagnoses of site specific colorectal cancer in Tumour Registry notifications and on death cerrificates

\begin{tabular}{|c|c|c|c|c|c|c|c|c|}
\hline \multirow[b]{2}{*}{ Tumour diagnosis } & \multicolumn{6}{|c|}{ Cause of death } & \multirow{2}{*}{$\begin{array}{l}\text { Total } \\
\text { deaths }\end{array}$} & \multirow[b]{2}{*}{ Alive } \\
\hline & $1530-1531$ & $1532-1533$ & $1538-1539$ & 154 & Other tumour & Not tumour & & \\
\hline \multirow{4}{*}{$\begin{array}{l}\text { Right part of the colon } \\
1530 \text {-1531 } \\
\text { Left part of the colon } \\
1532-1533 \\
\text { Colon, multiple or } \\
\text { not specified } \\
1538-1539 \\
\text { Rectum (anus included) } \\
154 \\
\text { Not in Tumour Registry }\end{array}$} & 11 & 0 & 18 & 1 & 2 & 9 & 41 & 21 \\
\hline & 0 & 10 & 11 & 0 & 2 & 7 & 30 & 10 \\
\hline & 3 & 1 & 13 & 1 & 0 & 1 & 19 & 5 \\
\hline & $\begin{array}{l}0 \\
0\end{array}$ & $\begin{array}{l}1 \\
0\end{array}$ & $\begin{array}{l}3 \\
6\end{array}$ & $\begin{array}{r}44 \\
0\end{array}$ & $\begin{array}{l}5 \\
-\end{array}$ & 20 & $\begin{array}{l}73 \\
-\end{array}$ & $\begin{array}{l}27 \\
-\end{array}$ \\
\hline
\end{tabular}

All diagnoses are transformed to ICD-7. Two deceased men with cancer of the appendix (ICD 1534) are omitted.

$0 \cdot 4 / 1000$ person-years. By contrast, among the fishermen the SIR was 0.97 (95\% CI $0 \cdot 70-1 \cdot 31$ ).

In all these analyses we used national rates for comparison. A reanalysis (except for the fishermen's cohort and the polyurethane cohort) with county specific rates gave similar results.

In the subgroup of asbestos cement workers with a cumulative asbestos dose exceeding $40 \mathrm{f}$-years $/ \mathrm{ml}, \quad(\mathrm{n}=78)$ there were three observed $v 0.6$ expected cancers in the right part of the colon (SIR 5.00; 95\% CI 1.03-14.7). Among cement workers with a minimum of 25 years of employment $(n=$ 370) there were seven observed $v 2 \cdot 0$ expected cancers in the right part of the colon (SIR 3.57; 95\% CI 1.43-7.36). By contrast, a similar inclusion criterion of a minimum of 25 years of employment in the cohorts of fishermen and other industrial workers did not affect the estimates of risk. For cancers in the left part of the colon, the SIRs did not change in any of the cohorts.

The corresponding SIRs for rectal cancer were $2 \cdot 13(95 \%$ CI $0 \cdot 26-7 \cdot 71)$ in the asbestos cement workers, 2.55 (95\% CI $1 \cdot 10-5 \cdot 04)$ in the cement workers, and $2 \cdot 21$ (95\% CI $1.23-3.64)$ in the other industrial workers. By contrast, the fishermen had an SIR of 0.87 (95\% CI 0.52-1.40).

\section{CHARACTERISTICS OF ALL CASES OF} COLORECTAL CANCERS

Cancers in the right part of the colon were verified by histology or cytology in $95 \%$ of the cases. The corresponding figures for the left part of the colon and rectum were $100 \%$ and $\mathbf{9 8 \%}$ respectively. One case of cancer was based on clinical examination only. Radiographic investigations, surgery, or necropsy without histological examination had been performed in the other cases. There were no significant differences in the diagnostic procedures between the different pooled cohorts.

The tumours with few exceptions were adenocarcinomas. In the right part of the colon there were four cancers that were noted as undifferentiated or malignant but unclassified. The corresponding figure for the left part of the colon was one, for the colon with unspecified location four, and for the rectum two. Also, there was one carcinoid in the appendix and one anal cancer.
COMPARISON BETWEEN CANCER MORBIDITY AND MORTALITY DATA

Of the 128 men with cancer in the colon defined by information from the cancer registry, $92(72 \%)$ had died. Only 68 of them had colon cancer noted as the cause of death; furthermore, only for 34 of them was the subsite stated in the death certificate the same as in the cancer registry notification (table 2). From the dead men, the sensitivity of mortality data, compared with cancer morbidity data, was as low as $27 \%$ for tumours in the right part of the colon and $33 \%$ for left sided tumours. The pattern of low sensitivity of subsite in the mortality data was seen in all the cohorts, and was explained mainly by the use of unspecified diagnoses of colon cancer in the death certificates. For rectal cancer the mortality data sensitivity was higher $(60 \%)$.

\section{Discussion}

We have found an increased incidence of cancers in the right part of the colon in asbestos cement workers, as well as in cement workers, with indications of a dose-response relation. By contrast, other industrial workers had a deficit of these tumours. Compared with the general population and the fishermen, the mineral exposed workers, as well as the other industrial workers, also had a slightly increased incidence of rectal cancer.

It can be assumed that the diagnostic accuracy concerning subsite is high, as the diagnosis was based on tissue specimens in more than $95 \%$ of the cases. Pathologists and cytologists report every diagnosis of cancer on surgically removed tissues, biopsies, cytological specimens, and necropsies, including forensic necropsies, to the Cancer Registry. Also, a report from the responsible physician is mandatory. Thus most cases were notified with two reports. Further, we have no indications that the diagnostic procedures varied between the cohorts.

The SIRs calculated in our cohorts of manual workers are based on rates in the general population that might underestimate the risk related to exposure, as blue collar workers have a lower risk of colon cancer, ${ }^{19}$ both in the right and the left part. ${ }^{20}$ The standardised (for age, region, and area of population density) incidence among blue collar workers in Sweden is reported to be about $0 \cdot 20 / 1000$ 
person-years in both the right and the left part of the colon. ${ }^{20}$ The proportion of right to left colon cancers among the fishermen was in good agreement with these data, whereas the finding among the other industrial workers was in contrast showing a deficit of cancers in the right part of the colon. Among the workers exposed to minerals the pattern was remarkably different, with an almost fivefold predominance of right sided tumours.

A high dietary intake of fat has been associated with an increased risk for cancer in the right part of the colon in a Swedish study. ${ }^{8}$ It is, however, not likely that there has been confounding by dietary factors of such a degree as to explain the observed differences in risk between the workers exposed to minerals and the other industrial workers. The protective effect of physical activity, which can be seen also after adjustment for confounding factors such as dietary habits, body mass, ${ }^{5}$ and social class, is most pronounced in the left part of the colon. To our knowledge the physical demands at work do not differ substantially between the cohorts of industrial workers. Thus, the different right to left ratio among the mineral workers cannot be explained by confounding risk factors that are linked to the socioeconomic group.

Despite numerous epidemiological and experimental studies, there is no consensus concerning exposure to asbestos and risks of gastrointestinal cancer. ${ }^{21-24}$ In a recent metaanalysis the risk for lung cancer was used as a surrogate for exposure. ${ }^{22}$ High exposure was said to have occurred if there was a twofold risk for lung cancer or more; otherwise it was said to be low. Mortality from colorectal cancer was evaluated in 15 populations, of which three consisted of asbestos cement workers. The relative risk for high exposure compared with reference populations was $1.6(95 \%$ CI 1.3-1.9), whereas low exposure displayed a non-significant deficit (relative risk $0.9 ; 95 \%$ CI $0 \cdot 7-1 \cdot 1)$. Site specific risks within the large bowel were not evaluated. For comparison, the SIR for colorectal cancer in the asbestos cement workers was 1.4 in our study.

In cohorts from the asbestos cement industry, mortality from gastrointestinal cancer, ${ }^{25-27}$ colorectal cancer, ${ }^{28}$ or cancer of the colon and rectum separately ${ }^{29}$ has not been increased. Rectal, but not colon cancer morbidity was slightly, but not significantly, in excess in a Danish cohort. ${ }^{30}$ In another Swedish asbestos cement factory there was a nearly significant increase of mortality from colorectal cancer, but no increased morbidity from gastrointestinal cancer allowing for a latency period. ${ }^{31}$ In our original asbestos cement cohort, there was a slightly increased mortality, and morbidity, in colorectal cancer although this was not statistically significant. ${ }^{13}$ A significant dose-response relation between cumulative dose and mortality, with a relative risk of 3.4 at an exposure of $\geqslant 40 \mathrm{f}$-years $/ \mathrm{ml}$ was found as well as a tendency towards such a relation also for morbidity.

Data from case referent studies, examining exposure to asbestos and risk of morbidity from colon cancer, do not show convincing evidence of an association. ${ }^{32-35}$ In one study, where analyses by the anatomical subsite were presented, there was a significant increase of cancer in the right part of the colon only. ${ }^{34}$ In another, neither cancer of the right nor left colon showed clear associations. ${ }^{35}$ The type and magnitude of exposure to asbestos is, however, poorly elucidated in these population based studies, and, probably, the exposures were low for most of the subjects.

It has been claimed that misclassification of peritoneal mesotheliomas in cohorts exposed to asbestos might explain an observed excess of gastrointestinal cancers. ${ }^{21}$ In our original asbestos cement cohort several pleural but no peritoneal mesotheliomas were found. Out of 76 gastrointestinal cancers diagnosed between 1958 and 1983, there were 60 specimens available for a histopathological review. For 58 tumours the original diagnosis was confirmed; for the other two the diagnosis was not clear, but was not consistent with mesothelioma. ${ }^{36}$ Of the 27 colorectal cancers among asbestos cement workers reported in our study, 25 were diagnosed before 1984; of these all 18 reviewed were confirmed, as were the two cancers occurring later on. In the cement factories no substantial exposure to asbestos had occurred, and the cohort had a deficit of lung cancers; no mesotheliomas were found according to data from the cancer registry. Thus our findings cannot be explained by the presence of unknown peritoneal mesotheliomas. Also, it is not likely that misclassified mesotheliomas would occur only at one specific subsite within the colon.

Except for a non-significantly raised SMR of 1.88 for rectal tumours in a registry based mortality study of cement workers, ${ }^{37}$ an enhanced risk for colorectal tumours in cement workers had not been described before our cohort study ${ }^{12}$ and population based case referent study. ${ }^{11}$ In the case referent study, which was performed in the community of one of the cement plants, no analysis for specific subsite was done. A reanalysis of the study however confirmed that the risk was confined to cancers in the right part of the colon and in the rectum.

Only in a few epidemiological cancer studies of workers exposed to inorganic dusts were results for separate sites within the large bowel reported. In a case-referent study of bowel cancer morbidity in young urban men, tumours in the rectum and, to a lesser degree the sigmoid colon, were associated with dusty jobs. ${ }^{3}$ There are several reports of an increased incidence of colorectal cancer in the engineering and automotive industry, associated with exposures to metal and wood dust, among other substances. ${ }^{38-42}$ No clear cut pattern between dust exposure, and cancer of the colon and rectum emerges. Also, colon cancer among workers engaged in the production of polypropylene powder ${ }^{43}$ and fibres ${ }^{44}$ has been reported.

In descriptive studies, blue collar workers 
in general do not show higher incidence of rectal cancer than other socioeconomic groups. ${ }^{19-20}$ The results among the fishermen are in good agreement with these data. The other industrial cohorts in this study were, however, with the exception of the reference cohort, originally assembled from industrial settings with suspected carcinogens of different kinds. We found an increased incidence of rectal cancer of the same magnitude among the workers exposed to minerals as among the other industrial workers, and also increasing risk estimates with increasing dose or duration of employment. This is an indication that rectal cancer in the workers exposed to minerals as well as in the industrial comparison group may be related to occupational factors.

Inhaled dusts and fibres can reach the gastrointestinal tract through lung clearance and mucociliary transport mechanisms, and subsequent swallowing. In the proximal parts of the colon, retrograde peristalsis churns and mixes the liquid stool, ${ }^{4}$ the traffic in and out of the lumen is heavy, and the transit time is relatively long. By contrast, the distal parts of the colon have a storage function. Thus there is a good possibility for ingested mineral dust and fibres to get in close contact with the mucosa in the proximal colon. Asbestos fibres have been demonstrated microscopically in the digestive tract. ${ }^{45-46}$ The normal diet contains a large number of carcinogenic compounds and their precursors and their concentration is highest in the proximal colon. Also, bile acids, which are promotors, have their greatest impact on the cancer process in the proximal colon. ${ }^{47}$ Persistent particles may have a non-specific irritating effect on the mucosa thereby decreasing its normal protective mechanisms and enhancing the effect of carcinogens. ${ }^{48}$

Workers exposed to mineral dust and fibres showed a substantially increased incidence of cancer only in the right part of the colon. Our findings thus clearly underline the importance of an appropriate disease classification, in accordance with the present expanding biological knowledge, in order not to obscure or underestimate possible effects of exposure. As the risk pattern differed substantially from that of the other manual workers, differences in diet, physical activity, or other socioeconomic factors can hardly explain the enhanced risk. Thus it is assumed that persistent mineral dust and fibres reaching the colonic mucosa are causative. Further support for this assumption is the finding that higher risk estimates occur in workers with higher exposure estimates.

We found about 0.4 extra cases of cancer in the right part of the colon $/ 1000$ personyears among the asbestos cement workers. For comparison, the corresponding figure for primary lung cancer was 0.8 , and for mesothelioma $0 \cdot 4$. The observed excess of cancer in the right colon is hence not neglectable. The risk estimates for cancer in the right part of the colon were equal in the asbestos cement and cement cohort. Dust measurements indicate that levels of total dust and cement dust had been considerably higher in the cement plants. Therefore, exposure to cement is not likely to be the sole explanation of the observed risk among the asbestos cement workers. Also, in the chrysotile mining industry, where there is no cement but a non-fibrous dust fraction, indications of dose-response relations between accumulated dust exposure and mortality from colorectal cancer have been shown. ${ }^{49}$

Our findings need to be verified in other cohorts of workers exposed to mineral dust,for example, quartz and fibres. Especially, asbestos fibre with no concomitant exposure to mineral dust should be examined. Also, exposure to other types of persistent dusts,for example, metal and polymer dust-needs to be studied. It should be stressed that the pattern of subsite specific risks was evident only when data for morbidity from cancer were used. Besides the reduction of the number of cases found in a mortality study, the serious drawback is that the reported causes of death usually are unspecified or inaccurate with regard to subsite.

Zoli Mikoczy and Lars Rylander assisted in the data analysis. Leif Johansson reviewed the histopathological specimens. The present reanalysis was financially supported from the Faculty present reanalysis was financially supported from the Faculty of Medicine, University of Lund. The original cohort studies were supported by the Swedish
Klippan Leatherworkers Fund.

1 Weisburger JH, Wynder EL, Horn CL. Nutritional factors and etiologic mechanisms in the causation of gastroinand etiologic mechanisms in the causation

2 Beart RW, Melton LJ, Maruta M, Dockerty MB, Frydenberg HB, O'Fallon MW. Trends in right and left-sided colon cancer. Dis Colon Rectum 1983;26: 393-8.

3 Peters RK, Garabrant DH, Yu MC, Mack TM. A casecontrol study of occupational and dietary factors in colorectal cancer in young men by subsite. Cancer Research 1989;49:5459-68.

4 Johnson LR, Christensen J, Jackson MJ, et al. Physiology of the gastrointestinal tract. New York: Raven Press, 1987.

5 Gerhardsson de Verdier M, Steineck G, Hagman U, Rieger $\AA$, Norell SE. Physical activity and colon cancer: a case-referent study in Stockholm. Int $\mathcal{F}$ Cancer 1990 46:985-9

6 Hill MJ. Bile acids and human colorectal cancer. In: Vahouny GV, Kritchevsky D, eds. Dietary fiber in health and disease. New York: Plenum Press, 1982.

7 McMichael AJ, Potter JD. Host factors in carcinogenesis: certain bile-acid metabolic profiles that selectively increase the risk of proximal colon cancer. $f$ Natl Cancer Inst 1985;75:185-92.

8 Gerhardsson de Verdier M, Hagman U, Steineck G, Rieger $\AA$, Norell SE. Diet, body mass and colorectal cancer: a case-referent study in Stockholm. Int $f$ Cancer cancer: a case-refer

9 Brownson RC, Hoar Zahm S, Chang JC, Blair A. Occupational risk of colon cancer. An analysis by anatomic subsite. Am $\mathcal{F}$ Epidemiol 1989;130:675-87.

10 Bufill JA. Colorectal cancer: evidence for distinct genetic categories based on proximal or distal tumour location. Ann Intern Med 1990;113:779-88.

11 Jakobsson $\mathrm{K}$, Attewell $\mathrm{R}$, Hultgren $\mathrm{B}$, Sjöland $\mathrm{K}$ Gastrointestinal cancer among cement workers: a casereferent study. Int Arch Occup Environ Health 1990; 62:337-40.

12 Jakobsson $\mathrm{K}$, Horstmann V, Welinder $\mathrm{H}$. Mortality and cancer morbidity among cement workers. $\mathrm{Br} \mathcal{F}$ Ind $\mathrm{Med}$ 1993;50:264-72.

13 Albin M, Jakobsson K, Attewell R, Johansson L, Welinder H. Mortality and cancer morbidity in cohorts of $\mathrm{H}$. Mortality and cancer morbidity in cohorts of
asbestos-cement workers and referents. Br $\mathcal{f}$ Ind Med asbestos-cement

14 Hagmar L, Bellander $T$, Englander V, Ranstam J, Attewell R, Skerfving S. Mortality and cancer morbidity among workers in a chemical factory. Scand $\mathcal{f}$ Work Environ Health 1986;12:545-51.

15 Hagmar L, Bellander T, Andersson C, Lindén K, Attewell $R$, Möller T. Cancer morbidity in nitrate fertilizer workers. Int Arch Occup Environ Health 1991;63:63-7.

16 Mikoczy Z, Hagmar L. Increased incidence of sarcomas and myelomas among leather tanners [abstract]. 24th Congress on Occupational health. Nice:1993. 
17 Hagmar L, Welinder H, Mikoczy Z. Cancer incidence and mortality in the Swedish polyurethane foam manufacturing industry. Br F Ind Med 1993;50:537-543.

18 Hagmar L, Lindén K, Nilsson A, Norrving B, Akesson B Schütz A, Möller T. Cancer incidence and mortality among Swedish Baltic Sea fishermen. Scand $\mathcal{f}$ Work Environ Health 1992;18:217-24.

19 Vågerö D, Persson G. Occurrence of cancer in socioeconomic groups in Sweden. Scand 7 Soc Med 1986; 14:151-60.

20 Gerhardsson M, Steineck G, Norell SE. Colorectal cancer in Sweden. A descriptive epidemiologic study. Acta Oncol 1990;29:855-61.

21 Doll R, Peto J. Asbestos. Effects on health of exposure to astestos. A report to the Health and Safery Commission. asbestos. A report to the Health and Safety Com

22 Frumkin H, Berlin J. Asbestos exposure and gastrointestinal malignancy review and meta-analysis. Am $\mathcal{f}$ Ind $M e d$ 1988;14:79-95.

23 World Health Organization. Occupational exposure limits for asbestos. Report prepared by an WHO meeting. Oxford, United Kingdom, 10-11 April 1989. Geneva: WHO; 1989.

24 Weiss W. Asbestos and colorectal cancer. Gastroenterology 1990;99:876-84.

25 Laquet LM, van der Linden $L$, Lepoutre J. Roentgenographic lung changes, asbestosis and mortality in a Belgian asbestos-cement factory. In: Wagner JC, ity in a Belgian asbestos-cement factory. In: Wagner JC, ed. Biological effects of mineral fibres. Lyon: International Agency for Researc
Sci Publ No 30.

26 Thomas HF, Benjamin IT, Elwood PC Sweetnam PM. Further follow-up study of workers from an asbestos cement factory. Br $\mathcal{f}$ Ind Med 1982;39:273-6.

27 Finkelstein MM. Mortality among employees of an Ontario asbestos cement factory. Am Rev Respir Dis 1984;129:754-61.

28 Hughes JM, Weill H, Hammad YY. Mortality of workers employed in two asbestos cement manufacturing plants. employed in two asbestos cem

29 Gardner MJ, Winter PD, Pannett B, Powell CA. Follow up study of workers manufacturing chrysotile asbestos cement products. $\mathrm{Br} \mathcal{F}$ Ind $\mathrm{Med}$ 1986;43:726-32.

30 Raffn E, Lynge E, Juel K, Korsgaard B: Incidence of cancer and mortality among employees in the asbestos cement industry in Denmark. Br F Ind Med 1989; 46:90-6.

31 Ohlson C-G, Hogstedt C. Lung cancer among asbestos cement workers. A Swedish cohort study and a review. Br F Ind Med 1985;42:397-402.

32 Spiegelman D, Wegman DH. Occupation-related risks for colorect

33 Fredriksson M, Bengtsson N-O, Hardell L, Axelson $\mathrm{O}$. Colon cancer, physical activity, and occupational exposures. A case-control study Cancer 1989;63: 1838-42.

34 Gerhardsson de Verdier M, Plato N, Steineck G, Peters JM. Occupational exposures and cancer of the colon and rectum. Am $\mathcal{F}$ Ind Med 1992;22:291-303.

35 Garabrant DH, Peters RK, Homa DM. Asbestos and colon cancer: lack of association in a large case-control study. Am $\mathcal{F}$ Epidemiol 1992;135:843-53.

36 Albin M, Jakobsson K, Johansson L, Skerfving S. Asbest och gastrointestinal cancer-uppföljning över en 30årsperiod antyder samband. Lakartidningen 1985. 82:4584. (In Swedish)

$37 \mathrm{McDowall}$ ME. A mortality study of cement workers. $\mathrm{Br}$ f Ind Med 1984;41:179-82.

38 Robinson C, Waxweiler RJ, McCammons CS. Pattern and model makers, proportionate mortality 1972-1978. and model makers, proportion

39 Swanson GM, Belle SH. Cancer morbidity among woodworkers in the U.S. automotive industry. $\mathcal{F}$ Occup Med 1982;24:315-9.

40 Park RM, Wegman DH, Silverstein MA, Maizlish NA, Mirer FE. Causes of death among workers in a bearing manufacturing plant. Am f Ind Med 1988;13:569-80.

41 Svensson BG, Englander V, Âkesson B, Attewell $R$ Skerfving S, Ericsson $\AA$, Möller T. Deaths and tumours among workers grinding stainless steel. Am $\mathcal{F}$ Ind Med among workers

42 Roscoe RJ, Steenland K, McCammon CS, Schober SE Robinson CF, Halperin WE, Fingerhut MA. Colon and stomach cancer mortality among automotive wood model makers. f Occup Med 1992;8:759-68.

43 Acquavella JF, Douglass S, Phillips SC. Evaluation of excess colorectal cancer incidence among workers involved in the manufacture of polypropylene. $\mathcal{F}$ Occup Med 1988;30:438-42.

44 Vobecky J, Devrode G, Caro J. Risk of large-bowel cancer in synthetic fibre manufacture. Cancer 1984;54: $2537-42$.

45 Huang J, Hisanaga N, Sakai K, Iwata M, Ono Y, Shibata $\mathrm{E}$, Takeuchi Y. Asbestos fibers in human pulmonary and extrapulmonary tissues. Am $\mathcal{F}$ Ind Med 1988; 14:331-9.

46 Ehrlich A, Gordon RE, Dikman SH. Carcinoma of colon in asbestos-exposed workers. Analysis of asbestos content in colon tissue. Am $\mathcal{F}$ Ind Med 1991;19:629-36.

47 Ames BN. Dietary carcinogens and anticarcinogens. Oxygen radicals and degenarative diseases. Science 1983;221:1256-64.

48 Correa P, Haenzel W, Cuello C, Tannenbaum S, Archer M. A model for gastric cancer epidemiology. Lancet 1975;2:58-9.

49 McDonald, JC, Liddell FDK, Gibbs GW, Eyssen GE McDonald A. Dust exposure and mortality in chrysotile mining, 1910-75. Br F Ind Med 1980;37:11-24.

\section{Correspondence and editorials}

Occupational and Environmental Medicine welcomes correspondence relating to any of the material appearing in the journal. Results from preliminary or small scale studies may also be published in the correspondence column if this seems appropriate. Letters should be not more than 500 words in length and contain a minimum of references. Tables and figures should be kept to an absolute minimum. Letters are accepted on the understanding that they may be subject to editorial revision and shortening.

The journal also publishes editorials which are normally specially commissioned. The Editor welcomes suggestions regarding suitable topics; those wishing to submit an editorial, however, should do so only after discussion with the Editor. 


\section{BOOK REVIEWS}

Calculated risks, 1st edition. BY JOSEPH RODRICKS (Pp 256; price $£ 17.95 \mathrm{H} / \mathrm{b}$, $f 9.95 \mathrm{P} / \mathrm{b}) .1992$. Cambridge: Cambridge University Press. ISBN (H/b): 052141191-2; ISBN (P/b): 0521-42331-7.

This readable and fascinating book provides an up to date introduction to toxicology and the safety evaluation of chemicals. Of even greater interest to lay readers and doctors alike, it lifts the scientific façade to reveal the inadequacies of quantitative risk assessment as practised in the United States by certain regulatory agencies for some years.

Rodricks devotes nine clearly written chapters to a systematic explanation of toxicological end points and test principles. $\mathrm{He}$ covers acute, chronic, reproductive, and genetic toxicity, carcinogenicity, and doseresponse. He then distinguishes carefully between toxicological hazard (the potentially harmful properties of a chemical) and risk (the probability that the relevant toxicological effect will actually occur) before turning to risk estimation.

Much of the balanced and sensible discussion that follows focuses on carcinogenicity - and with good reason. This is the area in which much unnecessary public anxiety has been produced by such media declarations (to quote one of his examples) as: "One person in every ten thousand will contract cancer from residues of EDB in flour. .." As the author explains, what the regulators themselves actually say when they announce the figure produced by a mathematical quantitative risk assessment model is always highly protected by elaborate bet-hedging, ifs and buts. But it matters little how the figure is hemmed around by conditions and qualifications, once the media seize on it.

The truth of the matter, as Rodricks points out, is that for most of the putative carcinogens (whether man made or natural) in food and the wider environment, there is usually little or no epidemiological information and, in the absence of human data, all that is left are the results of any animal studies that may have been conducted. There are enormous difficulties involved in estimating human carcinogenic risks quantitatively from rodent studies. There is, for example, the question of interspecies difference: but an even greater problem is the interpolation from very high doses in rodents (needed to achieve effects in studies containing only a few hundred animals), to the region of the dose-response curve relevant to the minute quantities that reach humans. In this very low-dose region, the shape of the curve (including the existence of any threshold) is always unknown.

Major assumptions therefore accompany the use of unvalidated quantitative risk assessment models, and it is hardly surprising that the different models yield widely differing results. In view of the many unknowns, regulators often play safe and use worst case assumptions; for example that the curve is linear in the low dose region and possesses no threshold. Worse still, the models take no account of toxicokinetic and mutagenicity data. Taken together, the omissions and worst case assumptions lead cumulatively to the upper bound risk figures, which breed public chemophobia, opportunistic politics, and unrealistic regulatory burdens, when the all important explanatory wording is overlooked.

The author provides a telling discussion of the legislative anomalies and inconsistencies that have arisen in the United States when these methods have been used to underpin the regulatory control of different categories of chemical products and contaminants. Finally, he offers his own suggestions for future improvements, and these are very much in line with the thinking of regulatory toxicologists in the United Kingdom.

G E DIGGLE

Lung Function. Assessment and Application in Medicine, 5th edition. By JE COTES. With the editorial collaboration of GL LEATHART (Pp 768). 1993. Oxford: Blackwell Scientific Publications. ISBN: 0-632-03526-9.

Lung Function by John Cotes is an institution, as much a part of a lung function laboratory as a Douglas bag. After a gap of 12 years a fifth edition has been published. As before the book provides a practical guide for testing lung function with the relevant physiological background, and a strong emphasis on standardisation and reference values. The format is broadly as before but the book has been extensively revised. This edition has some surprises-a fascinating introduction on how atmospheric oxygen concentrations have changed over the last few billions of years and the possible changes in the future if the Gaia hypothesis of James Lovelock is correct. It also, believe it or not, contains cartoons-but not many. The layout has been changed and is generally improved although the printing was faint in parts of our copy-for example page 110 where the superscripts on one equation are not legible.

The book maintains many of the features, good and less good, that have characterised Lung Function in the past. Its strengths are its care over methodological detail for the practising lung function technician and research worker, the wide range of reference values and its breadth. The chapter on normal values has always been particularly useful and this has now been extended to cover reference values from the European Coal and Steel Community in addition to those for several other groups including adults of African and Indian descent, United States adults, men from Pakistan working in the United Kingdom, new born babies, young infants, and normal values in children and young adults. There are some useful new tables - for example, $8 \cdot 2$-although some are less helpful-for example, $6 \cdot 1$. The book is strongest when the various tests that are available are discussed, how they should be carried out, and their interpretation. The emphasis on detail and standardisation allows laboratories to set up new techniques and be reasonably confident that they can produce reliable data. Lung function testing is approached from the viewpoint of a physiologist and may sometimes seem a little impractical to a busy clinician or fieldworker. It may be ideal, as Cotes suggests, to obtain a flow volume loop every time you measure FEV, but this is not possible in busy clinical practice and in many epidemiological circumstances. Details of management-for example, table $16 \cdot 13$ - are inadequate and would be better omitted.

In chapter 3 Cotes tackles the difficult problem of numerical treatment of results with illustrative examples. Some of these are difficult to follow or rather small printexplaining when coefficient of variation is and is not appropriate would have been helped by a figure. More discussion on the assessment of repeatability would have been welcome.

The physiological background is approached rather mathematically and assumes some knowledge of lung physiology. What would be regarded as basic and important respiratory physiology, for a registrar in training, for example, is mixed with sometimes less than clear discussions of rather esoteric areas of lung physiology. Discussion of the equal pressure point and flow limitation is a case in point, not helped by figure $5 \cdot 15$. Some old tests-for example, the Riley bubble method for assessing blood gas tensions-are retained whereas some of the newer techniques such as challenge tests are given insufficient space. The index was always the most frustrating aspect of this book, the chance of obtaining a page number on first attempt being fairly small. Look up "anatomical dead space" and you read "see dead space, anatomical".

These reservations are minor and there is no doubt that Lung Function with this new edition will continue to be the best laboratory reference book for lung function measurements as it has been for many years. We congratulate John Cotes on maintaining such a high standard and for the help that this has given to lung function technicians, research fellows, and respiratory physicians over the years.

AE TATTERSFIELD BG COOPER

\section{CORRECTION}

Asbestos, cement, and cancer in the right part of the colon (1994;51:95-101). During the technical editing stage, two numbers were inadvertently changed in the right hand part of table 1 . The correct version is given here.

\begin{tabular}{lccl}
\hline Rectum & & & \\
\hline ICD 154 & & & \\
\hline$O$ & $E$ & $S I R$ & $(95 \% C I)$ \\
\hline 13 & 7.87 & 1.65 & $(0.88-2.83)$ \\
11 & 7.17 & 1.53 & $(0.77-2 \cdot 75)$ \\
24 & 15.0 & 1.60 & $(1.03-2 \cdot 41)$ \\
1 & 0.91 & & \\
11 & 7.32 & & \\
13 & 7.05 & & \\
2 & 1.17 & & \\
1 & 0.57 & & \\
3 & 2.72 & & \\
1 & 1.32 & & \\
32 & 21.1 & 1.52 & $(1.05-2 \cdot 17)$ \\
44 & 45.6 & 0.97 & $(0.70-1.31)$ \\
\hline
\end{tabular}

